\title{
Evaluation of the results of regional metrology organisation comparisons and national inter-laboratory comparisons for electrical quantities
}

\author{
Oleh Velychko", Tetyana Gordiyenko², Stanislav Karpenko ${ }^{1}$ \\ ${ }^{1}$ State Enterprise "Ukrmetrteststandard", 4, Metrolohychna str., 03143, Kyiv, Ukraine \\ ${ }^{2}$ Odesa State Academy of Technical Regulation and Quality, 15, Kovalska str., 65020, Odesa, Ukraine
}

\begin{abstract}
The global metrological traceability fully depends on the implementation of international mutual recognition agreements in field of metrology. The linked results of international comparisons of national standards for alternating current/direct current (AC/DC) voltage transfer difference measurements and electrical power measurements, and national inter-laboratory comparison AC/DC voltage transfer difference and electrical power measurements at industrial frequency was presented. The main goal of this inter-laboratory comparison was the assessment of calibration laboratories capabilities that perform calibration in AC/DC voltage transfer difference and electrical power measurements. The consistency of the data obtained using the $E_{n}$ numbers and $\chi^{2}$ test was estimated.
\end{abstract}

\section{Section: RESEARCH PAPER}

Keywords: Comparison of standards; inter-laboratory comparison; calibration laboratory; measurement uncertainty

Citation: Oleh Velychko, Tetyana Gordiyenko, Stanislav Karpenko, Evaluation of the results of regional metrology organisation comparisons and national inter-laboratory comparisons for electrical quantities, Acta IMEKO, vol. 9, no. 2, article 4, June 2020, identifier: IMEKO-ACTA-09 (2020)-02-04

Editor: Alexandru Salceanu, Technical University of lasi, Romania

Received December 26, 2019; In final form March 18, 2020; Published June 2020

Copyright: This is an open-access article distributed under the terms of the Creative Commons Attribution 3.0 License, which permits unrestricted use, distribution, and reproduction in any medium, provided the original author and source are credited.

Corresponding author: Oleh Velychko, e-mail: velychko@hotmail.com

\section{INTRODUCTION}

The global metrological traceability fully depends on the implementation of two Mutual Recognition Agreements (MRAs): the International Committee on Weights and Measures (CIPM) [1] and the International Laboratory Accreditation Cooperation (ILAC) [2]. Metrological traceability at the highest level is ensured by international comparisons of National Metrology Institutes (NMIs) and Designated Institutes (DIs) standards, and metrological traceability at lower levels is ensured by the calibration of working standards in NMIs and DIs or accredited calibration laboratories [3]-[7].

The results of international comparisons of standards of NMIs and DIs of different countries [8]-[12] are used to implement the provisions of the CIPM MRA. Key comparisons are made by the CIPM consultative committees and six Regional Metrology Organizations (RMOs) using agreed technical protocols for the participants. RMOs make supplementary comparisons for those measurements that are not covered by key comparisons, consultative committees, or RMOs. Results of key and supplementary comparisons are published in a special key comparison database - that of the International Bureau of Weights and Measures (BIPM) [13].

The results of the calibration of working standards and measuring instruments, conducted by accredited calibration laboratories for accredited test laboratories [14], are used to implement the provisions of the ILAC MRA. Inter-laboratory comparisons are widely used to confirm the technical competence of accredited calibration laboratories [15]-[21].

Nowadays, AC voltage and electrical power measurements at industrial frequencies have practical importance, as they have become the main basis of the commercial relationships between electricity consumers and electricity suppliers. It should be noted that the main purpose of legal metrology is to control the measuring instruments that are used in commercial transactions and to ensure and guarantee the accuracy of the measurement results throughout the period of use under operating conditions within the limits of the allowed permissible errors.

It is certain that inter-laboratory comparison reports [22] can provide information on where a calibration laboratory that participated in the comparison may need improvement. It should be noted that comparing different results can only be done 
correctly if the measurement uncertainty of the results is taken into account [4][14].

An important task in the technical confirmation of metrological traceability is to establish both a connection between the results of comparisons of national standards [23] [25] and a linking of the calibration results of accredited calibration laboratories within the framework of national interlaboratory comparisons [7][26][27]. The basis for establishing such a connection should be provided by the NMIs or DIs.

The procedure of the linking between key or supplementary comparison results and national inter-laboratory comparison results is described in Section 2. The proposed procedure is applied to AC/DC-voltage transfer difference measurements (Section 3) and AC power measurements (Section 4). The general recommendations for the laboratories that participated in the inter-laboratory comparisons (ILCs) for AC/DC-voltage transfer difference measurements and $\mathrm{AC}$ power measurements are presented in Section 5.

\section{DESCRIPTION OF THE METHOD}

Reference values, their measurement uncertainty, degrees of equivalence, and uncertainties for all participants are determined in the evaluation of the results of the RMO comparisons. In the data evaluation, RMO key comparisons are determined: transformed participant data and their uncertainties; degrees of equivalence, and measurement uncertainty for all participants, with the exception of the linking NMIs and DIs [14].

The following procedure is used in the evaluation of interlaboratory comparison data with calibration laboratory participation: assigned value and its measurement uncertainty; inter-laboratory differences - degrees of equivalence and their uncertainties; and data consistency characteristics. There are various options to establish an assigned value, particularly the measured value by the reference laboratory, which ensures metrological traceability to the national standard. When conducting an inter-laboratory comparison for calibration laboratories, it is necessary to ensure the stability of the reference sample [18].

To establish the linking between the results of international comparisons of standards and the results of inter-laboratory comparisons, the optimal is the participation of the NMI or DI as a reference laboratory. The general approach used for the evaluation of RMO comparison data and inter-laboratory comparison data is provided in [7][26][27].

Inter-laboratory differences or degrees of equivalence for the $i$-th calibration laboratory traditionally defined by:

$$
D_{l a b i}=X_{l a b i}-X_{A V},
$$

where $X_{l a b i}$ is measured value for the $i$-th calibration laboratory, and $X_{A V}$ is the assigned value, which is determined by the reference laboratory.

The expanded uncertainty of $U_{A V}$ measurements is determined by:

$$
U_{A V}=k \sqrt{u^{2}\left(X_{A V}\right)+u^{2}\left(X_{s t a b}\right)},
$$

where $k$ is the coverage factor (traditionally $k=2) ; u\left(X_{A V}\right)$ is the standard uncertainty obtained during the calibration of the measuring instruments of the reference laboratory; $u\left(X_{\text {stab }}\right)$ is the standard uncertainty about the instability of the measuring instruments during the inter-laboratory comparison.
The expanded uncertainty $U_{A V}$ of the $i$-th calibration laboratory in the inter-laboratory comparison is determined by:

$$
U\left(D_{\text {lad } i}\right)=k \sqrt{u^{2}\left(X_{A V}\right)+u^{2}\left(X_{\text {lab } i}\right)} .
$$

The results of the inter-laboratory comparison are expressed in relation to the RMO comparison: $D_{N M I j}=X_{N M I j}-X_{R V}$. For this purpose, the degrees of equivalence of the inter-laboratory comparison (indicated $D_{\text {lab } i}$ ) are corrected by a correction factor $d$, which is determined based on the results of the participant laboratory in both comparisons (NMIj-lab1):

$$
d=D_{N M I j}-D_{l a b 1},
$$

where $D_{N M I j}$ refers to the degrees of equivalence of the NMI or DI $i$ in the RMO comparison; $D_{l a b i}$ refers to the degrees of equivalence of lab1 (NMI $\imath$ ) in the inter-laboratory comparison, with the uncertainty:

$$
U(d)=k \sqrt{\left[u^{2}\left(D_{N M I j}\right)+u^{2}\left(D_{l a b 1}\right)\right] / 2}
$$

The corrected degrees of equivalence for the $i$-th laboratory participant in the inter-laboratory comparison with respect to linking it to the RMO comparison are estimated as:

$$
D_{l a b i}^{\prime}=D_{l a b i}+d
$$

with the expanded uncertainty:

$$
U\left(D_{\text {labi } i}^{\prime}\right)=k \sqrt{u^{2}\left(D_{l a b i}\right)+u^{2}(d)} .
$$

$E_{n}$ numbers are calculated using this equation:

$$
E_{n}=\frac{D_{l a b i}}{\sqrt{U_{\text {lab } i}^{2}-U_{A V}^{2}}}
$$

where $U_{\text {lab } i}$ is the expanded uncertainty of a participant's result.

An inter-laboratory comparison result is satisfactory if $\left|E_{n}\right| \leq 1$, showing the compatibility of the measurement results. In other words, if $\left|E_{\mathrm{n}}\right|>1$, the result of the inter-laboratory comparison is unsatisfactory.

According to [10], on the basis of measurement results and associated uncertainties presented by the participants of RMO comparisons of national measuring standards, we need to calculate the value of the $\chi^{2}$ test.

The same formula from [10] can be applied to the evaluation of the consistency of the results of inter-laboratory comparisons for calibration laboratories:

$$
\chi^{2}=\sum_{i=1}^{n} \frac{D_{l a b i}{ }^{2}}{u^{2}\left(x_{l a b i}\right)}
$$

To check the consistency of inter-laboratory comparisons for calibration laboratories, a criterion value is used, which is calculated based on data provided by the calibration laboratories. The criterion value does not exceed the critical value $\chi^{2}$ for confidence level 0.95 and the number of degrees of freedom $n-1$ ( $n$ is the number of the calibration laboratory participants in the inter-laboratory comparison):

$$
\chi^{2}<\chi_{0.95(n-1)}^{2}
$$




\section{RESULTS OF THE AC/DC VOLTAGE TRANSFER DIFFERENCE}

The results of the Euro-Asian Cooperation of National Metrological Institutions (COOMET) COOMET.EM-S1 supplementary comparison (VNIIM ${ }^{1}$, Russia, and UMTS, Ukraine) [28] is expressed in terms of the reference value of the COOMET.EM-K6.a key comparison (VNIIM, UMTS, BelGIM,

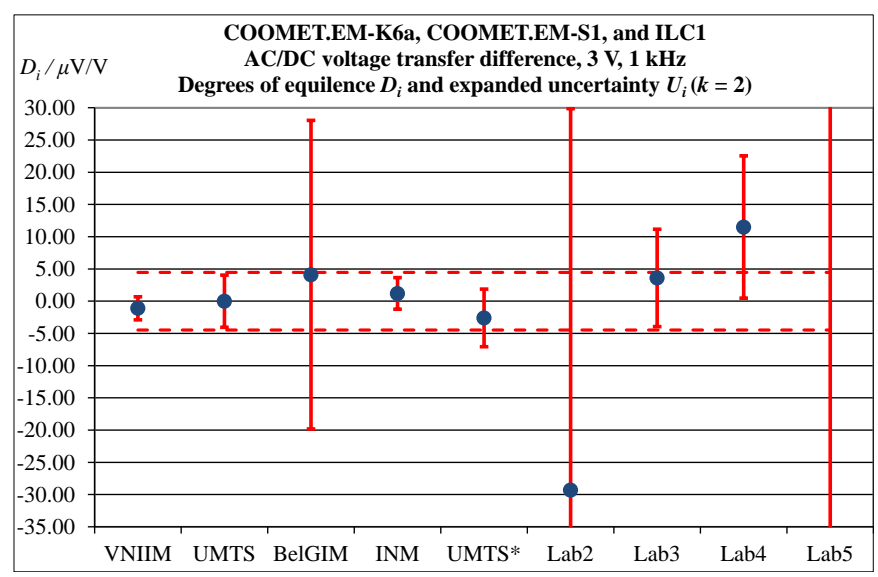

Figure 1. Degrees of equivalence of all laboratories for COOMET.EM-K6.a, COOMET.EM-S1 comparisons and ILC1 in terms of RV $\mathrm{V}_{\kappa 6 . a}$ at frequency of $1 \mathrm{kHz}$.

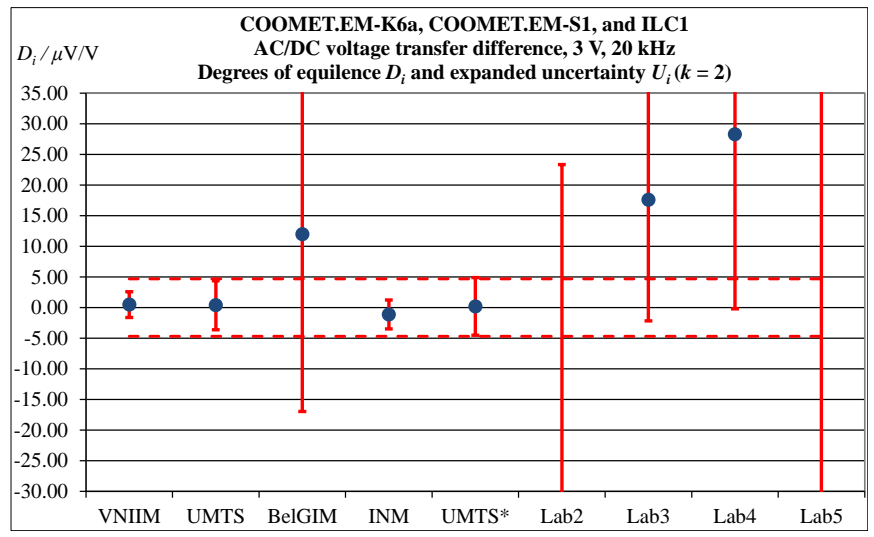

Figure 2. Degrees of equivalence of all laboratories for COOMET.EM-K6.a, COOMET.EM-S1 comparisons and ILC1 in terms of $\mathrm{RV}_{K 6 . a}$ at frequency of $20 \mathrm{kHz}$

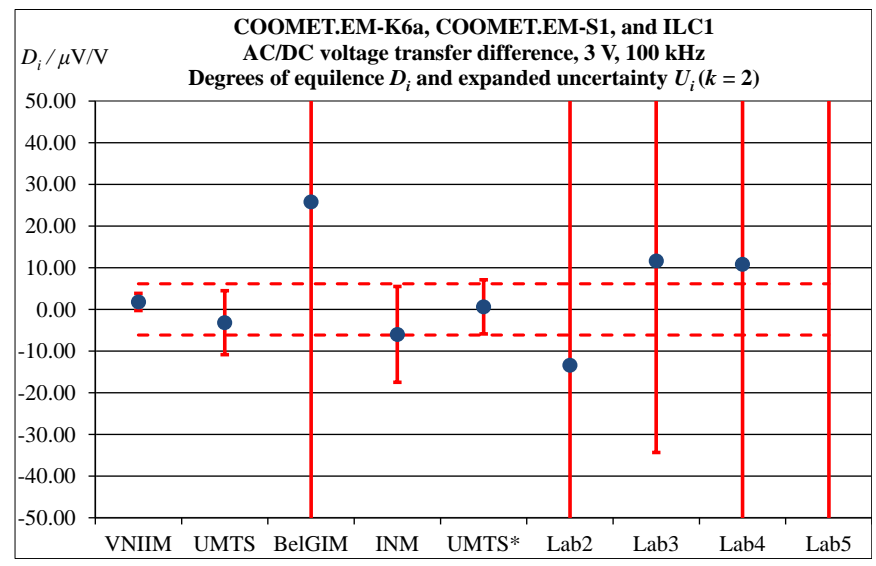

Figure 3. Degrees of equivalence of all laboratories for COOMET.EM-K6.a, COOMET.EM-S1 comparisons and ILC1 in terms of RV $\mathrm{K}_{6 . a}$ at frequency of $100 \mathrm{kHz}$.
Belarus, INM, Romania) [29]. VNIIM (Russia) took part both in COOMET.EM-K6.a and COOMET.EM-S1 comparisons therefore it can serve as a linking NMI for these two comparisons.

The results from all participant laboratories in COOMET.EM-K6.a, COOMET.EM-S1, and national ILC1 (five participants) in terms of $R V_{K 6 . a}(1 \mathrm{kHz}, 20 \mathrm{kHz}$, and 100 $\mathrm{kHz}$ ) are shown in Table 1 [27]. $D_{K 6 a}$ is degrees of equivalence from COOMET.EM-K6.a, and $D_{S 1}$ is degrees of equivalence from COOMET.EM-S1; $U\left(D_{K 6 a}\right)$ is the NMI's or DI's expanded uncertainty from COOMET.EM-K6.a, $U\left(D_{S 1}\right)$ is the NMI/DI expanded uncertainty from COOMET.EM-S1, and $U\left(D_{I L C 1}\right)$ is the expanded uncertainty of the $i$-th calibration laboratory from ILC1.

In accordance with the proposed procedure and using the data in Table 1, the degrees of equivalence for all the participant laboratories in the COOMET.EM-K6.a and COOMET.EM-S1 comparisons as well as national ILC1 in terms of $R V_{K 6 . a}$ with the expanded uncertainty at frequencies of $1 \mathrm{kHz}, 20 \mathrm{kHz}$, and 100 $\mathrm{kHz}$ were calculated, as shown in Figure 1-Figure 3. UMTS took part both in the COOMET.EM-K6.a and COOMET.EM-S1 comparisons and national ILC1; therefore, it can serve as a linking laboratory (reference laboratory).

The results of the estimation of the $E_{n}$ numbers and $\chi^{2}$-test of all participant laboratories in COOMET.EM-K6.a and COOMET.EM-S1 comparisons and national ILC1 are shown in Table 2. Results for all NMIs/DIs and Lab participants are satisfied except Lab $4\left(E_{n}=1.04\right)$ at frequency $1 \mathrm{kHz}$ (require correction of the calibration procedure).

\section{RESULTS FOR ELECTRICAL POWER STANDARDS}

The results of COOMET.EM-S2 supplementary comparison (UMTS, BelGIM and BIM, Bulgaria) [30] expressed in terms of the reference value of EURAMET.EM-K5.1 key comparison (12 participants) [31]. UMTS took part both in EURAMET.EMK5.1 and COOMET.EM-S2 comparisons therefore it can serve as a linking NMI for these two comparisons. The different travelling standards were used in these comparisons.

UMTS as a pilot laboratory organized and conducted the COOMET.EM-S2 supplementary comparison in power for power factors $1.0,0.5 \mathrm{Lag}, 0.5 \mathrm{Lead}$, AC voltage $120 \mathrm{~V}$, AC current $5 \mathrm{~A}$ at frequencies of $50 \mathrm{~Hz}$ and $53 \mathrm{~Hz}$ [30]. The radial scheme was used.

Radian Research RM 15-04 was selected as travelling standard for this comparison. RM 15-04 is precision single-phase electrical power meter, works on principles of digital processing of electrical current and voltage signals and well-suited for test applications that require multiple measurements with high accuracy and stability. In addition to its auto ranging capabilities, RM 15-04 features three summing current inputs which can be used to perform closed link testing.

Currently there are about twenty Ukrainian accredited calibration laboratories, but only seven calibration laboratories took part was in ILC2 which organized by UMTS to maintain their accreditation. The main goal of ILC2 was the assessment of calibration laboratory capabilities that perform calibration in power measurement. This inter-laboratory comparison helped to verify first of all technical competence of the staff of participated calibration laboratories, their technical and calibration procedures, environmental conditions [22].

\footnotetext{
${ }^{1}$ For Abbreviations, see end of the article.
} 
Table 1. Degrees of equivalence of laboratories in COOMET.EM-K6.a, COOMET.EM-S1 comparisons and ILC1 in terms of RV K6.a. $_{\text {. }}$

\begin{tabular}{|c|c|c|c|c|c|c|c|c|}
\hline Lab & $D_{K 6 a}, \mu \mathrm{V} / \mathrm{V}$ & $U\left(D_{K 6 a}\right), \mu \mathrm{V} / \mathrm{V}$ & $D_{s 1}, \mu \mathrm{V} / \mathrm{V}$ & $U\left(D_{s_{1}}\right), \mu \mathrm{V} / \mathrm{V}$ & $D_{I L C 1}, \mu \mathrm{V} / \mathrm{V}$ & $U\left(D_{I L C 1}\right), \mu V / V$ & $D^{\prime}{ }_{K 6 a}, \mu \mathrm{V} / \mathrm{V}$ & $U\left(D^{\prime}{ }_{\kappa 6 a}\right), \mu \mathrm{V} / \mathrm{V}$ \\
\hline \multicolumn{9}{|c|}{$1 \mathrm{kHz}$} \\
\hline VNIIM & -1.10 & 1.79 & -0.50 & 1.50 & & & -1.10 & 1.79 \\
\hline UMTS & 0.00 & 4.04 & & & & & 0.00 & 4.04 \\
\hline BelGIM & 4.10 & 23.94 & & & & & 4.10 & 23.94 \\
\hline INM & 1.20 & 2.44 & & & & & 1.20 & 2.44 \\
\hline UMTS* (Lab 1) & & & -2.00 & 4.10 & 0.00 & 4.47 & -2.60 & 4.47 \\
\hline Lab 2 & & & & & -26.70 & 59.00 & -29.30 & 59.17 \\
\hline Lab 3 & & & & & 6.20 & 6.10 & 3.60 & 7.56 \\
\hline Lab 4 & & & & & 14.10 & 10.10 & 11.50 & 11.04 \\
\hline Lab 5 & & & & & -48.70 & 260.00 & -51.30 & 260.04 \\
\hline \multicolumn{9}{|c|}{$20 \mathrm{kHz}$} \\
\hline VNIIM & 0.48 & 2.11 & -1.20 & 1.50 & & & 0.48 & 2.11 \\
\hline UMTS & 0.38 & 3.99 & & & & & 0.38 & 3.99 \\
\hline BelGIM & 11.98 & 28.94 & & & & & 11.98 & 28.94 \\
\hline INM & -1.12 & 2.37 & & & & & -1.12 & 2.37 \\
\hline UMTS* (Lab 1) & & & -1.50 & 4.20 & 0.00 & 4.50 & 0.18 & 4.70 \\
\hline Lab 2 & & & & & -42.00 & 65.00 & -41.82 & 65.17 \\
\hline Lab 3 & & & & & 17.40 & 19.20 & 17.58 & 19.77 \\
\hline Lab 4 & & & & & 28.10 & 28.10 & 28.28 & 28.49 \\
\hline Lab 5 & & & & & 68.20 & 3140.00 & 68.38 & 3140.00 \\
\hline \multicolumn{9}{|c|}{$100 \mathrm{kHz}$} \\
\hline VNIIM & 1.81 & 2.06 & -3.80 & 3.00 & & & 1.81 & 2.06 \\
\hline UMTS & -3.19 & 7.67 & & & & & -3.19 & 7.67 \\
\hline BelGIM & 25.80 & 139.00 & & & & & 25.80 & 139.00 \\
\hline INM & -5.99 & 11.50 & & & & & -5.99 & 11.50 \\
\hline UMTS* (Lab 1) & & & -5.00 & 5.80 & 0.00 & 8.50 & 0.61 & 6.15 \\
\hline Lab 2 & & & & & -14.00 & 95.00 & -13.39 & 95.20 \\
\hline Lab 3 & & & & & 11.00 & 45.50 & 11.61 & 45.91 \\
\hline Lab 4 & & & & & 10.20 & 78.70 & 10.81 & 78.94 \\
\hline Lab 5 & & & & & 1419.00 & 3140.00 & 1419.61 & 3140.01 \\
\hline
\end{tabular}

Table 2. The results of estimation of $E_{n}$ numbers and $\chi^{2}$-test for ILC1.

\begin{tabular}{|c|c|c|c|}
\hline Lab & $E_{n}$ & $\chi^{2}$ & $\chi^{2} 0.95(n-1)$ \\
\hline \multicolumn{4}{|c|}{$1 \mathrm{kHz}$} \\
\hline VNIIM & 0.61 & 2.58 & 3.33 \\
\hline UMTS & 0.00 & & \\
\hline BelGIM & 0.17 & & \\
\hline INM & 0.49 & & \\
\hline UMTS* (Lab 1) & 0.58 & & \\
\hline Lab 2 & 0.50 & & \\
\hline Lab 3 & 0.48 & & \\
\hline Lab 4 & 1.04 & & \\
\hline Lab 5 & 0.20 & & \\
\hline \multicolumn{4}{|c|}{$20 \mathrm{kHz}$} \\
\hline VNIIM & 0.23 & 2.65 & 3.33 \\
\hline UMTS & 0.10 & & \\
\hline BelGIM & 0.41 & & \\
\hline INM & 0.47 & & \\
\hline UMTS* (Lab 1) & 0.04 & & \\
\hline Lab 2 & 0.64 & & \\
\hline Lab 3 & 0.89 & & \\
\hline Lab 4 & 0.99 & & \\
\hline Lab 5 & 0.02 & & \\
\hline \multicolumn{4}{|c|}{$100 \mathrm{kHz}$} \\
\hline VNIIM & 0.88 & 1.57 & 3.33 \\
\hline UMTS & 0.42 & & \\
\hline BelGIM & 0.19 & & \\
\hline INM & 0.52 & & \\
\hline UMTS* (Lab 1) & 0.09 & & \\
\hline Lab 2 & 0.14 & & \\
\hline Lab 3 & 0.25 & & \\
\hline Lab 4 & 0.14 & & \\
\hline Lab 5 & 0.45 & & \\
\hline
\end{tabular}

Table 3. Degrees of equivalence of laboratories in COOMET.EM-S2 comparison and ILC2 in terms of RV $\mathrm{R}_{S 2}$.

\begin{tabular}{|c|c|c|c|c|c|c|}
\hline Lab & $\begin{array}{c}D_{s 2}, \\
\mu P / P\end{array}$ & $\begin{array}{c}U\left(D_{s 2}\right) \\
\mu \mathrm{P} / \mathrm{P}\end{array}$ & $\begin{array}{l}D_{I L C 2,} \\
\mu \mathrm{P} / \mathrm{P}\end{array}$ & $\begin{array}{c}U\left(D_{I L C 2}\right), \\
\mu \mathrm{P} / \mathrm{P}\end{array}$ & $\begin{array}{c}D_{s 2,}^{\prime} \\
\mu \mathrm{P} / \mathrm{P}\end{array}$ & $\begin{array}{c}U\left(D_{s 2}^{\prime}\right), \\
\mu \mathrm{P} / \mathrm{P}\end{array}$ \\
\hline \multicolumn{7}{|c|}{ power factor $=1.0$} \\
\hline BelGIM & 33.9 & 36.6 & & & 33.9 & 36.6 \\
\hline BIM & -3.0 & 9.8 & & & -3.0 & 9.8 \\
\hline UMTS* (Lab 1) & 8.5 & 17.4 & 0.0 & 12.3 & 8.5 & 17.4 \\
\hline Lab 2 & & & 6.0 & 82.2 & -2.5 & 83.1 \\
\hline Lab 3 & & & 566.0 & 150.5 & 557.5 & 151.0 \\
\hline Lab 4 & & & 76.0 & 145.0 & 67.5 & 145.5 \\
\hline Lab 5 & & & 46.0 & 104.5 & 37.5 & 105.2 \\
\hline Lab 6 & & & 46.0 & 100.0 & 37.5 & 100.8 \\
\hline \multicolumn{7}{|c|}{ power factor $=0.5 \mathrm{Lag}$} \\
\hline BelGIM & 60.4 & 59.2 & & & 60.4 & 59.2 \\
\hline BIM & -2.7 & 16.4 & & & -2.7 & 16.4 \\
\hline UMTS* (Lab 1) & 29.3 & 45.7 & 0.0 & 13.0 & 29.3 & 45.7 \\
\hline Lab 2 & & & 22.0 & 82.0 & -7.3 & 83.0 \\
\hline Lab 3 & & & 282.0 & 150.6 & 252.7 & 151.2 \\
\hline Lab 4 & & & 112.0 & 152.0 & 82.7 & 152.6 \\
\hline Lab 5 & & & -18.0 & 101.1 & -47.3 & 101.9 \\
\hline Lab 6 & & & -8.0 & 70.0 & -37.3 & 71.2 \\
\hline \multicolumn{7}{|c|}{ power factor $=0.5$ Lead } \\
\hline BelGIM & -17.0 & 59.3 & & & -17.0 & 59.3 \\
\hline BIM & 2.7 & 16.7 & & & 2.7 & 16.7 \\
\hline UMTS* (Lab 1) & -0.2 & 46.7 & 0.0 & 13.0 & -0.2 & 46.7 \\
\hline Lab 2 & & & 18.0 & 82.0 & 18.2 & 83.0 \\
\hline Lab 3 & & & 308.0 & 150.6 & 308.2 & 151.2 \\
\hline Lab 4 & & & 78.0 & 140.5 & 78.2 & 141.1 \\
\hline Lab 5 & & & -22.0 & 101.1 & -21.8 & 101.9 \\
\hline Lab 6 & & & -12.0 & 70.0 & -11.8 & 71.2 \\
\hline
\end{tabular}




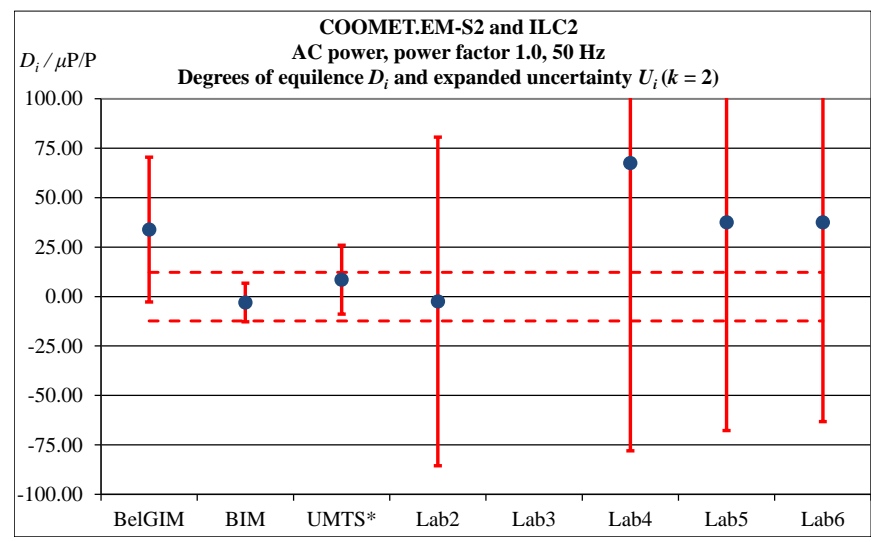

Figure 4. Degrees of equivalence of all laboratories for COOMET.EM-S2 comparisons and ILC2 in terms of $\mathrm{RV}_{S 2}$ for power factor $=1.0$.

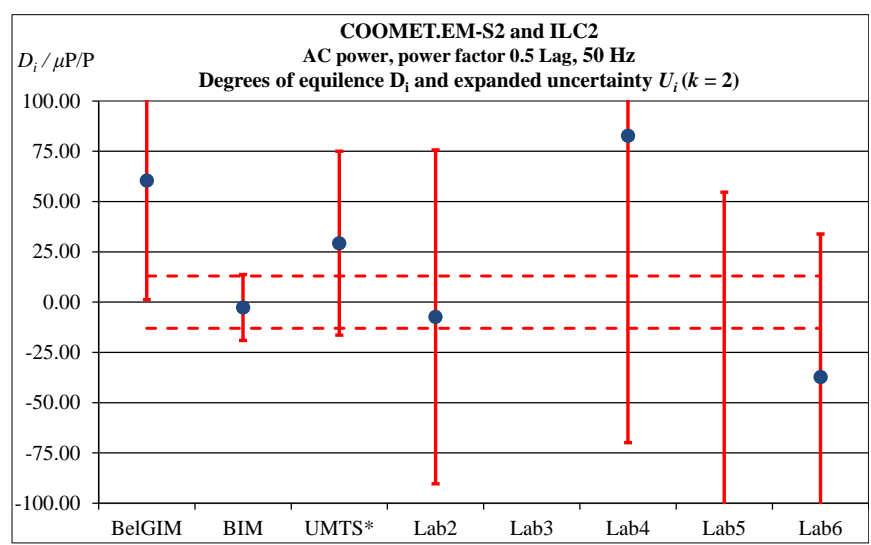

Figure 5. Degrees of equivalence of all laboratories for COOMET.EM-S2 comparisons and in ILC2 in terms of $R V_{s 2}$ for power factor $=0.5 \mathrm{Lag}$.

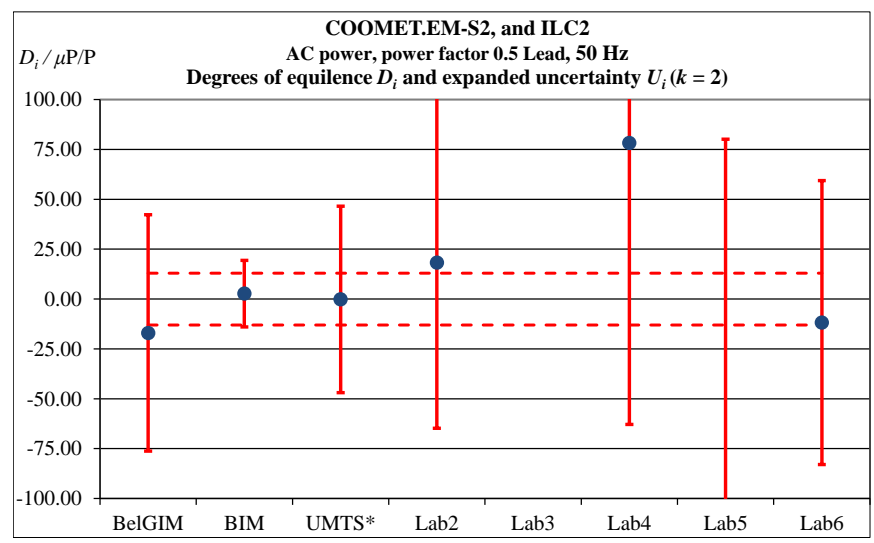

Figure 6. Degrees of equivalence of all laboratories for COOMET.EM-S2 comparisons and ILC2 in terms of $\mathrm{RV}_{S 2}$ for power factor $=0.5$ Lead.

$D_{S 2}$ is degrees of equivalence from COOMET.EM-S2; $U\left(D_{S 2}\right)$ is NMI's/DI's expanded uncertainty from COOMET.EM-S2, $U\left(D_{I L C 2}\right)$ is expanded uncertainty of $i$-th calibration laboratory from ILC2.

In accordance with the proposed procedure and using the data in Table 3, degrees of equivalence for all laboratories for COOMET.EM-S2 comparisons and national ILC2 in terms of $\mathrm{RV}_{S 2}$ with the expanded uncertainty at frequency of $50 \mathrm{~Hz}$ was calculated, which are shown on Figure 4-Figure 6. UMTS took part both in COOMET.EM-S2 comparison and national ILC2 therefore it can serve as a linking Lab (reference laboratory).

The results of estimation of $E_{n}$ numbers and $\chi^{2}$-test of all participant laboratories in COOMET.EM- S2 comparison and
Table 4. The results of estimation of $E_{n}$ numbers and $\chi^{2}$-test for ILC2.

\begin{tabular}{|c|c|c|c|}
\hline Lab & $E_{n}$ & $x^{2}$ & $\chi^{2} 0.95(n-1)$ \\
\hline \multicolumn{4}{|c|}{ power factor $=1.0$} \\
\hline BelGIM & 0.93 & 1.67 & 2.73 \\
\hline BIM & 0.31 & & \\
\hline UMTS* (Lab 1) & 0.49 & & \\
\hline Lab 2 & 0.03 & & \\
\hline Lab 3 & 3.69 & & \\
\hline Lab 4 & 0.46 & & \\
\hline Lab 5 & 0.36 & & \\
\hline Lab 6 & 0.37 & & \\
\hline \multicolumn{4}{|c|}{ power factor $=0.5 \mathrm{Lag}$} \\
\hline BelGIM & 1.02 & 2.27 & 2.73 \\
\hline BIM & 0.16 & & \\
\hline UMTS* (Lab 1) & 0.64 & & \\
\hline Lab 2 & 0.09 & & \\
\hline Lab 3 & 1.67 & & \\
\hline Lab 4 & 0.54 & & \\
\hline Lab 5 & 0.46 & & \\
\hline Lab 6 & 0.52 & & \\
\hline \multicolumn{4}{|c|}{ power factor $=0.5$ Lead } \\
\hline BelGIM & 0.29 & 0.54 & 2.73 \\
\hline BIM & 0.16 & & \\
\hline UMTS* (Lab 1) & 0.00 & & \\
\hline Lab 2 & 0.22 & & \\
\hline Lab 3 & 2.04 & & \\
\hline Lab 4 & 0.55 & & \\
\hline Lab 5 & 0.21 & & \\
\hline Lab 6 & 0.17 & & \\
\hline
\end{tabular}

national ILC2 are shown in Table 4. Results for all NMI/DI and Lab participants are satisfied except Lab $3\left(E_{n}=3.69\right.$ for power factor $=1.0, E_{n}=1.67$ for power factor $=0.5 \mathrm{Lag}, E_{n}=2.04$ for power factor $=0.5$ Lead). Lab 3 result was excluded when calculating of $\chi^{2}$-test (require correction of the calibration procedure).

\section{GENERAL RECOMMENDATIONS FOR CALIBRATION LABORATORIES}

The comparative analysis of the results of provided by the relevant calibration laboratories allow the following general recommendations to be drawn:

Lab1, Lab2, Lab3, and Lab5 for ILC1 meet the established requirements $\left(\left|E_{\mathrm{n}}\right| \leq 1\right)$ when calibrating the travelling standard at frequency of $1 \mathrm{kHz}$ confirming the qualification of the participated calibration laboratory, therefore do not require any corrections in their work;

Lab 4 for ILC1 only has an unsatisfactory result at a frequency of $1 \mathrm{kHz}\left(E_{n}=1.04\right)$; therefore, it requires correction in the calibration procedure.

Lab1, Lab2, Lab3, Lab4, and Lab5 in ILC1 meet the established requirements $\left(\left|E_{n}\right| \leq 1\right)$ when calibrating the travelling standard at frequencies of $20 \mathrm{kHz}$ and $100 \mathrm{kHz}$, confirming the qualification of the participated calibration laboratory; therefore, they do not require any corrections.

Lab1, Lab2, Lab4, Lab5, and Lab6 for ILC1 meet the established requirements of the criterion $\left(\left|E_{\mathrm{n}}\right| \leq 1\right)$ when calibrating the travelling standard for $120 \mathrm{~V}, 5 \mathrm{~A}$, power factor $=$ 1.0, 0.5 Lag, and $0.5 \mathrm{Lead}$ at a frequency of $50 \mathrm{~Hz}$, confirming the qualification of the participant calibration laboratory; therefore, they do not require any corrections. 
Concerning Lab3 in ILC2, failures were only detected in the measurements for $120 \mathrm{~V}, 5 \mathrm{~A}$, power factor $=1.0,0.5 \mathrm{Lag}$, and $0.5 \mathrm{Lead}$ at a frequency of $50 \mathrm{~Hz}$; therefore, it requires a serious correction in the calibration procedure.

General recommendations for Lab 4 in ILC1 and Lab3 in ILC2 follow:

to review the existing calibration procedures or develop new ones in accordance with the requirements of international standards for accredited laboratories;

to reconsider the approaches to the evaluation of the measurement uncertainty in the applied calibration procedures, in accordance with which the evaluation of the expanded uncertainty was performed; and

to systematically carry out technical training for laboratory staff to perform the calibration of measuring equipment and pay special attention to the provisions of international and national documents for the evaluation of measurement uncertainty.

\section{CONCLUSIONS}

The proposed procedure for linking the results of international comparisons of national standards and interlaboratory comparison results has been applied to AC/DC voltage transfer difference measurements and AC power measurements. The presented linked results showed good agreement between all participant laboratories. To check the consistency of the linked results, the $E_{n}$ number and $\chi^{2}$ test were used.

Participation in inter-laboratory comparisons provides independent verification of a calibration laboratory's competence and demonstrates to the public, customers, accreditation bodies, regulators, and laboratory management that procedures are under control and gives stakeholders technical confidence in the service which calibration laboratory provide.

The positive results of calibration laboratories that participated in the inter-laboratory comparisons mean the metrological traceability to the NMI or DI of accredited calibration laboratories through the periodical calibration of their standards.

\section{REFERENCES}

[1] CIPM, Mutual Recognition Agreement, 1999. [Online]. Available: https://www.bipm.org/utils/en/pdf/CIPM-MRA-2003.pdf

[2] ILAC B7:10/2015, the ILAC Mutual Recognition Arrangement, 2015 , p. 8.

[3] International Vocabulary of Metrology - Basic and General Concepts and Associated Terms (VIM), 3rd edition, JCGM 200, 2012. [Online]. Available:

https://www.bipm.org/utils/common/documents/jcgm/JCGM 200_2012.pdf

[4] Uncertainty of Measurement - Part 3: Guide to the Expression of Uncertainty in Measurement (GUM), JCGM 100, 2008. [Online] Available:

https://www.bipm.org/utils/common/documents/jcgm/ICGM 1002008 E.pdf

[5] ILAC P10:01/2013, ILAC Policy on Traceability of Measurement Results, 2013. [Online]. Available: https://ilac.org/publications-and-resources/ilac-policy-series/

[6] O. Velychko, Traceability of measurement results at different levels of metrological work, Measurement Techniques 52 (2009) pp. $1242-1248$.

[7] O. Velychko, T. Gordiyenko, Metrological traceability at different measurement levels, in: Standards, Methods and Solutions of Metrology. L. Cocco (editor). IntechOpen, London, United Kingdom, 2019, p. 102.
[8] CIPM, MRA-D-05:2016, Measurement comparisons in the context of the CIPM MRA, 2016, p. 29.

[9] COOMET R/GM/14:2016, Guidelines for Data Evaluation of COOMET Key Comparison, 2016, p. 6.

[10] COOMET R/GM/19:2016, Guideline on COOMET Supplementary Comparison Evaluation, 2016, p. 5.

[11] M. G. Cox, The Evaluation of Key Comparison Data. Metrologia 39 (2002) pp. 589-595.

[12] G. Mana, E. Massa, M. Predescu, Model selection in the average of inconsistent data: an analysis of the measured Planck-constant values, Metrologia 49 (2012) pp. 492-500.

[13] The BIPM Key Comparison Database (KCDB). [Online]. Available: http://kcdb.bipm.org/

[14] ISO/IEC 17025:2005, General Requirements for the Competence of Testing and Calibration Laboratories.

[15] ISO/IEC 17043:2010, Conformity Assessment - General Requirements for Proficiency Testing.

[16] ISO 13528:2015, Statistical Methods for use in Proficiency Testing by Interlaboratory Comparisons.

[17] S. F. Beckert, G. E. Fischer, Interlaboratory comparison of roughness measurement: application of Algorithm A of ISO 13528:2015 in determining the designated value and the standard deviation, Proc. of the XXII World Congress of the International Measurement Confederation, Belfast, United Kingdom, 3-6 September 2018, Journal of Physics: Conf. Series 1065 (2018), Art. No., 082007.

[18] J. J. L. Sousa, L. T. S. Leitao, M. M. Costa, M. C. Faria, Considerations on the influence of traveling standards instability in an interlaboratory comparison program, Proc. of the XX IMEKO World Congress: Metrology for Green Growth, 9-14 Sept., 2012, Busan, Republic of Korea, p. 4.

[19] P. Briggs, Proficiency testing for calibration laboratories, Proc. of the XX IMEKO World Congress: Metrology for Green Growth, 9-14 Sept., 2012, Busan, Republic of Korea, p. 5.

[20] J. Claudio, M. Costa, Brazilian energy interlaboratory program applicative, Proc. of the XX IMEKO World Congress: Metrology for Green Growth, 9-14 Sept., 2012, Busan, Republic of Korea, p. 6.

[21] I. Sandu, L. Dragomir, B. Pantelimon, Interlaboratory comparison, Proc. of the 15th IMEKO TC 4 Symposium, Iasi, 1517 July, 2007, p. 4.

[22] O. Velychko, S. Karpenko, Interlaboratory comparison for electric power measurements at industrial frequency in Ukraine, Proc. of the 23rd IMEKO TC4 Symposium, 17-20 Sept., 2019, Xi'an, China, 4 p. 4.

[23] O. Velychko, Possibilities of linking results of key and supplementary comparisons in field of electricity and magnetism, Measurement 144 (2019) pp. 167-172.

[24] O. Velychko, Linking results of key and supplementary comparisons of AC/DC voltage transfer standard, International Journal of Metrology and Quality Engineering 9 (2018), p. 7.

[25] O. Velychko, S. Karpenko, Linking results of key and supplementary comparisons of regional metrology organization for electrical power, International Journal of Metrology and Quality Engineering 7 (2016) Art. No. 301.

[26] O. Velychko, T. Gordiyenko, Linking Results of International Comparisons of the National Standard and the National InterLaboratory Comparisons, Journal of Physics: Conf. Series, IOP Publication 1065 (2018), Art. No. 072004.

[27] O. Velychko, T. Gordiyenko, Linking results of RMO comparisons and inter-laboratory comparisons for $\mathrm{AD} / \mathrm{DC}$ voltage transfer difference, Proc. of the 23rd IMEKO TC4 Symposium, 17-20 Sept., 2019, Xi'an, China, p. 4.

[28] G. P. Telitchenko, Supplementary bilateral comparison of the national AC/DC voltage transfer references between VNIIM (Russia) and Ukrmetrteststandard (Ukraine) (COOMET.EM-S1), Metrologia 54 (2017) p. 01004. 
[29] O. Velychko, Yu. Darmenko, Final report on COOMET key comparison of AC/DC voltage transfer references (COOMET.EM-K6.a), Metrologia 53 (2016) p. 01011.

[30] O. Velychko, S. Karpenko, V. Gachok, A. Akhmadov, Final report on COOMET 344/UA/05 supplementary comparison of $50 / 53 \mathrm{~Hz}$ power (COOMET.EM-S2), Metrologia 52 (2015) p. 01008.

[31] H. Çayci, Final report on key comparison EURAMET.EM-K5.1 (EURAMET Project No. 687): comparison of $50 / 60 \mathrm{~Hz}$ power, Metrologia 48 (2011) p. 01009.

\section{ABBREVIATIONS}

BelGIM - Belarusian State Institute of Metrology, Belarus

BIM - Bulgarian Institute of Metrology, Bulgaria

INM - National Institute of Metrology, Romania

UMTS - State Enterprise "Ukrmetrteststandard", Ukraine

VNIIM - D. I. Mendeleev Institute for Metrology, Russia 